\title{
ACHEGAS AO DICIONÁRIO DOS ANIMAIS DO BRASIL, DE RODOLPHO VON IHERING.
}

\author{
J. de Paiva Carvalho (1) \\ E
}

Paulo Sawaya (2)

O Dicionário dos Animais do Brasil, de Rodolpho von Ihering, publicado em 1940, é uma das obras mais importantes que no dominio das Ciências Naturais se editaram no Brasil, nestes últimos dez anos. A quantidade de informações que contém e o modo por que são apresentadas, marcam-lhe a originalidade e a importância, induzindo o leitor a interessar-se pela vida dos animais característicos da fauna neotrópica. A elaboração do Dicionário exigiu do autor - um dos provectos zoólogos brasileiros, na opinião de ArTur NeIVA - esforço e paciência durante algumas décadas, pois a impressão preliminar de uma parte da obra data da 1914. Quasi 30 anos, portanto, de trabalho continuado, no coletar informações aquí e ali, por todo o nosso Pais.

Iniciado o Dicionário quando $R$. von IHERING ainda pertencia ao quadro dos naturalistas do Museu Paulista - fundado pelo grande zoólogo, Prof. Dr. Hermann von Ihering - mesmo depois de afastado da importante instituição científica, o autor não descuidou do trabalho tão auspiciosamente iniciado. Benditas, pois, aquelas "horas de lazer" em que "a título de recreação intelectual, poude, lentamente, avolumar e retocar o Dicionário" (p. 3). Tal esforço, embora fragmentário - pois foi dispendido entre o tumultuar de uma vida que longe estava de ser confortavel - conseguiu êle, apaixonado que era da Zoologia, dar-nos o excelente volume de 898 páginas, contendo cerca de 2.800 verbetes.

A obra é fruto de uma tenacidade e de um entusiasmo impares, e para ela muito concorreu o amparo e o carinho da família excepcionalmente unida e afetiva de que Rodolpho von IHERING fruia o apôio indispensável para obra de tão grande vulto. Poderão dize-lo os amigos que compartilharam das altenrnativas de suas atividades, de que, porém, resultou labor sempre fecundo. Estáva R. vON IHERING sempre voltado para as cousas de nossa Pátria, no anseio muito justo de fazer algo de grande numa ciência em que seu ilustre progenitor já firmará reputação internacional. É, pois, de toda justiça que nesta breve intro-

(1) Do Instituto Paulista de Oceanografia.

(2) Do Departamento de Fisiologia Geral e Animal - Fac. Fil. Cien. Letras. Univ. de São Paulo. CAIXA POSTAL 2926, SÃO PAULO. 
dução de nosso modesto trabalho, rendamos a homenagem merecida a quem tanto fez pelo desenvolvimento da Zoologia no Brasil.

Aparecido o Dicionário em 1940, recebemo-l. alvic’re ramente e a sua leitura constituiu nossa preocupação predileta. Foi então que deliberamos, seguindo o exemplo do autor, ir anotando os vocábulos ainda não registrados no Dicionário e que colhemos de nossas leituras e em nossas viagens pelo País, no mesmo exercício profissional de estudar a nossa fauna. Seguimos, neste particular, a excelente diretriz de R. VON IHERING, de "sobrepor o critério da bôa escolha à ânsia de aumentar rapidamente e a todo o transe, o número de vocábulos" (p. 14). E, agora, decorridos dez anos neste trabalho não raro bem árduo, julgamos azado o momento de publicar estas achegas ao seferido Dicionário. Contem elas, não somente verbeies novos de uso corrente, como ainda algumas anotações que nos parecem de utilidade acrescentar aos verbetes registrados. Estas anotações foram cuidadosamente elaboradas tendo em vista os progressos constantes e mais recentes da Zoologia, de modo particular na sua fisionomia moderna, qual seja a experimental. Apraz-nos pois trazer a lume esta modesta contribuição ao Dicionário dos Animais do Brasil, de RoDoLPHO voN IHERING que, sem dúvida, passará a ser conhecido, como é atualmente, "DicionárIo DE RODOlPho von IHERING" e que indicaremos pelas iniciais D.R.V.I. no curso de nossos comentários.

Apenas duas observações julgamos oportuno fazer no sentido de contribuir para melhorar o D.R.v.I. A primeira refere-se à designação das famílias zoológicas em português. Infelizmente ainda não há acôrdo, entre os nossos diversos interessados na Zoologia, na tradução para o português dos nomes zoológicos providos da terminação idae, que como se sabe é privativa das designações das famílias. Ora, sendo estas designações femininas em latim, dever-se-á, ao nosso ver, manter-se o mesmo gênero em português. Seriam, portanto, femininos os nomes indicativos de famílias em nossa lingua. Assim, por exemplo, as familias Falconidae, Belonidae, Cichlidae, etc., corresponderiam a Falcônidas, Belônidas, Cíclidas, etc., Acontece, porém, que para estas traduções o D. R. v. I. registra a terminação ideos, como também o fazem vários autores brasileiros, designando aquelas famílias por Falconideos, Belonideos, Ciclideos, etc., Preferiremos manter, em nossos rápidos comentários, a designação correta de Falcônidas, Belônidas, Cíclidas e assim por deante, até que uma convenção entre os interessandos resolva esta questão nomenclatural. A outra observação refere-se à sinonimia dos nomes vulgares. O D. R. v. I. dá, a partir da pg. 889 , a relação de nomes vulgares organizada por classes. No decorrer de nossas anotações encontrámos numerosos nomes vulgares, dos quais vários não gravados no D. R. v. I. e que pertencem à sinonimia de outros indicados na obra, e também numerosos outros nela não referidos. Seria mais interessante que a nova edição que por ventura se fizer trouxesse esta relação em ordem rigorosamente alfabética, com 
a indicação da página onde se encontra o termo sinônimo. Com isto . evitar-se-ia o aumento excessivo de verbetes, como aliás se encontra no Dicionário, é verdade em número ainda pequeno, como estes: Acarí - o mesmo que Guacarí; Acutimbóia - veja-se sob Cutimbóia; Agarrador - o mesmo que Peixe Piolho, e assim muitos outros. Á vista destas considerações, resolvemos dar a lista dos respectivos vocábulos sinônimos na ordem alfabética, no final de cada letra destas achegas, lista que poderia ser aproveitada na redação da nova edição.

Finalmente, informam-nos que o D.R.v.I. se acha exgotado. Mais uma razão a justificar a publicação destas achegas, que poderão ser utilizadas pelo editor da nova edição, e que esperamos venha a lume tão breve quanto possivel.

ABACATUAIA - Nome empregado por Marcgrave para designar o peixe da familia Carangidae, Argyreiosus vomer LACÉPÈDE. Alguns léxicos registram $A B A C U T A I A$.

ABELHA DO REINO - A este verbete acrescentariamos os resultados das investigações extremamente interesantes de K.v. FrIsch, sobre a "dança" e outros hábitos das abelhas. A Apis é capaz de distinguir o cheiro da essência de laranjeira de 43 extratos etéreos diferentes. O limite de percepção dos odores é muito próximo do do homem. O sentido do gosto, porem, não é tão desenvolvido; muitas substâncias que nos sabem doces são sem gosto para as abelhas. Em sua volta à colmeia a abelha é influenciada por vários fatores dentre os quais o principal é a direção dos raios solares. Os acidentes naturais ao redor da colmeia são reconhecid่os por estes insetos $\varepsilon$ servem para identificar-lhes o local. O saracoteio das abelhas ("dança" das abelhas) foi descoberto por v. FRISCH e consiste em o animal descrever primeiro um semicírculo

à esquerda, voltar pelo meio e

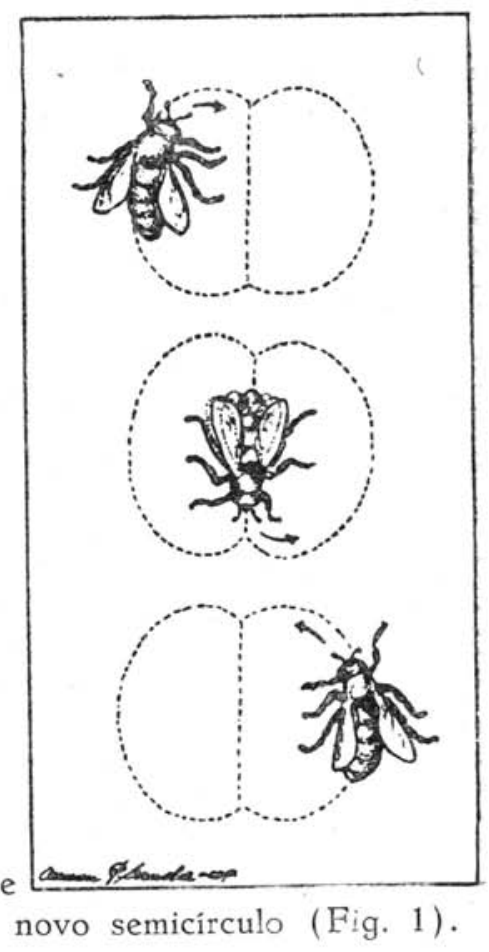
seguir para a direita descrevendo novo semicírculo (Fig. 1). 
. Juntamente com o "rodeio" teriam estes movimentos significação na "linguagem" com que estes insetos se comunicam uns com os outros.

ABELHAS SOCIAIS INDIGENAS. - O D.R.v.I. registra diversas diferenças entre estas abelhas $e$ as abelhas do reino. Segundo Graetz as Trigona têm olfato muito mais acurado que a. Apis.

ABOBORA - Nome dado a uma borboleta da familia Heliconidae, gênero Eueides.

ACANGOERA - Certa espécie de gavião que vive nas cabeceiras dos rios Xingú e Jeraoçú, no Amazonas, e que fazem ver o retrato das antigas harpias, na cara humana que tem (Dic. Port. Bras.Frei Onofre). Supomos tratar-se do Cutucurim, Gavião de Penacho, Gaviãoreal ou Uiraçú - Harpia harpyja (L.), do Amazonas, Bahia, Minas Gerais, Pará, Paraná e S. Paulo.

ACARÁ - Valeria a pena anotar os hábitos singulares deste peixe e dos demais da familia das Cíclidas. Os Acarás caracterizam-se pelo cuidado que dispensam aos filhotes. Logo depois de ecloidas as lavras, o casal toma conta da ninhada. Se algum inimigo se aproxima, escondem os filhotes na cavidade bucal para soltálos logo que os vêm isentos de perigo.

ACARÁ BERÊRÊ - Peixe da família Cichlidae, Mesonauta festivum (HECK.).

ACARÁ BÔBO - Peixe da família Cichlidae, Aequidens dorsigerys (HECK.).

ACARÁ CASCUDO - Peixe da família Cichlidae, Cichlaurus bimaculatus (L.).

ACARÁ CHIBANTE - Peixe da família Chichlidae, Geophagus jurupari Heck. O mesmo que JURUPARI-PINDÁ.

ACARÁ DOLA - Peixe da família Cichlidae, Aequidens tetramerus (НЕСК.).

ÀCARÁ FUSO - Peixe da família Chichlidae, Cichlasoma psittacus Heck.

ACARÁ FUSO - Peixe da fam. Balistidae, Balistes carolinersis GM., também chamado ACARÁ MUCÚ.

ACARÁ FirRAMBOCAIA - Peixe da família Cichlidae, Aequidens vittatus (НЕCK.).

ACARÁ PIXúNA - Peixé da familia Cichlidae, Cichlasoma coryphaenoides Heck.

ACARÁ TINGA - Peixe da família Eucinostomidae, Diapterus brasilianus Cuv \& VAl. Denominação dada à G U I R A T I NGA ou G A R Ç A B A N C A G A N D, Casmerodius albus egretta GM., 
ÁCARO - O D.R.v.I. iegistra o termo distinguindo algumas familias de Carrapatos. Seria interessante anotar também que são em geral hematófagos e susceptiveis de transmitir molestias. Picam de preferências os animais de sangue quente, isto é, Áves e Mamiferos, mas são encontrados também grudados à pele de Sapos e à quitina dos Besouros. Os que chupam sangue apresentam o fato característico de efetuarem a digestão desta substância com o auxílio de certos cogumelos, por meio de micetomas. É o tipo da chamada digestão por simbiontes muito frequente entre os hematófagos. Os ácaros aquáticos são muitos numerosos, de colorido vistoso.

ACINÉTIDAS ou ACINETIDEOS - Infusórios com tentáculos ou sugadores que se alimentam de outros infusórios e cujo típo é a Acineta. Quando as vitimas tocam a Acineta ficam paralizadas pela secreção tóxica emitida pelos tentáculos.

ACRÍDIDAS ou ACRIDIDEOS - Insetos Ortópteros que tem por tipo o Gafanhoto.

ACRíDIO - Gafanhoto. Referente ou semelhante ao Gafanhoto.

ACUMATANGA - Papagaio do leste do Brasil, Amazonas rhodocoryta (SAlvadori).

ACUTIPUM - Macaco pequeno, de pele felpuda e crespa, do Norte do Brasil.

AGRIMENSOR - Nome que se dá às larvas de certa borboleta da família Geometridae.

ÁGUA - VIVA - Seria interessante acrescentar o fato de os animais do gênero Rhizostoma, assinalado no D.R.v.I. se alimentarem frequentemente dos chamados caranguejos aranha. Ao toparem com uma das águas vivas na praia, quasi sempre por entre as franjas que guarnecem a boca, existe um caranguejo morto. Justamente nas Rhizostoma a chamada boca não se continúa com o esôfago, pois este é obliterado. Assim sendo, o animal para alimentar-se bombardeia os crustáceos com as vesículas urticantes imobilisando-os. Assim, é-lhes fácil prendelos entre as franjas bucais e, depois de seguros, sobre êles secretar o "suco digestivo", ácido, o qual os vai amolecendo até transformá-los em uma papa que, então, é sugada através de canais até a cavidade gástrica.

ÁGUIA CHILENA - Áve de rapina, do gênero Geranoaetus, G. melanoleucus melanoleucus (VIEILlot), do Brasil Meridional.

ÁGUIA CINZENTA - Áve de rapina, do gênero Harpuphaliaetus, $H$. coronatus (Vieillot), do Brasil Meridional e Ocidental.

AIEREBA - Além do que vem mencionado no D.R.v.I. valeria acrescentar que o acúleo caudal destas raias quando atinge a vitima provoca ferimentos que os pescadores do norte do Bra- 
lugares distantes, com o que diminuiram cs insetos. Seria, pois, em última análise, a falta de alimento que obrigou estas áves abandonarem a "Casa das andorinhas".

ANELÍDEOS - Vermes de corpo segmentado, caracterizados por terem respiração cutânea e branquial e sangue vermelho. Locomovem-se, em geral, por meio de cerdas. Vivem na terra úmida, como as minhócas ou na água doce, como as senguessugas ou na salgada, como a Nereis.

ANEQUIM - Não seria demais indicar também que este Tubarão possui nas mandibulas várias fileiras de dentes. À medida que as da primeira fileira vão caindo os demais fazem, imediatamente, a substituição. Sendo muito vorazes, como assinala o D.R.v.I., engolem com rapidez abóboras quentes que os marujos lhes lançam para caça-los. Queimados internamente, morrem e ao darem à tona são apanhados.

ANFIOXO - Animal marinho, de tamanho pequeno, que vive enterrado na areia de determinadas praias. A espécie comum à costa brasileira é o Branchiostoma platae Hubss. Possúe a corda dorsal inteira permanentemente no adulto.

ANFIPODOS - Crustáceos com olhos sesseis, de corpo lateralmente comprimido, que vivem na água doce e salgada, muitos dos quais levam vida parasitária (ecto-parasitos). Figuram como prinpais representantes os gêneros Gammarus, Phronima, Caprella e Cyamus, todos ocorrentes em águas brasileiras.

ANIJÚ-ACANGA - Nome do Camaleão, Enyalius catenatus, re gistrado por Gabriel SoARes e ocorrente de São Paulo ao Nordeste.

ANODONTES - Moluscos acéfalos, de água doce, providos de concha bivalva. Não possuem bysso, movimentando-se por meio de um pé carnoso, muito desenvolvido.

ANOFELINOS - Mosquitos, dos mais nocivos, entre os quais figura o gênero ANOPHELES e outros que, por meio de suas picadas, transmitem febres, como a maleita. Vide mosquito.

ANOMUROS - Crustáceos decapodos representado, em águas brasileiras, por diversos gêneros, tais como: Dromia, Pagurus, Porcellana, Aegla, etc.

ANORí - Nome que, no Norte do Brasil, se dá ao macho do T R A C A J A.

ANTA - Valeria a pena dizer que um dos maiores inimigos deste animal é a nossa Onça Pintada.

ANTEDON - Equinodermas da classe Crinoidea, dos quais a fauna brasileira possúe tres ou mais espécies.

ANTENÁRIO - Peixes da familia Antennariidae, em que figuram os gêneros Histrio e Antennarius.

ANTOZOÁRIOS - Celenterados que compreendem as Actineas, os Corais e Madréporas. Vide C OR A L. 
AÔLO - Nome dado pelos índios Parecis ao PAPAGAIO CAMPEIRO ou AJURú-APÁRA, Amazona ochrocephala ochrocerhala (GMELin), do noroeste do Brasil.

APAIARí - Como os demais peixes da familia Cichlidae, este também tem um cuidado todo especial pelos filhótes. Os Apaiarís fazem pequenas covas no fundo da lagoa ou do corrego, e para uma delas transportam, com a boca, as pequeninas larvas que sairam dos óvos depositados sobre um substrato duro, como seja tijolo, pedra, pedaço de madeira, etc. As covas são construidas somente depois da postura. O número de óvos de cada postura é de cerca de 1.200 e deles o casal não se afasta até que as larvas possam nadar livremente. Assim mesmo protegem a ninhada durante muito tempo. As larvas dos Apaiarís têm na cauda riquissima rede vascular, que serve para a respiração como foi acentuado por Sawaya \& Maranhão.

APANHA MOSCA - Nome dado às pequenas aranhas da família Salticidae.

APERTA - Nome que, na região do rio Ribeira de Iguape (E. de São Paulo), se dá a uma espécie de cascudo.

ÁPIDAS - Diz-se dos representantes de himenópteros que têm por tipo a ABELH A.

AFLISIA - Nome que se dá a um molusco opistobrânqui desprovido de manto e de concha e que, ao ser excitado, segrega um liquido escuro contido em suas glândulas branquiais. É o único meio de defesa que o animal possúe.

ÁPODOS - Diz-se dos anfíbios de aspecto colubriforme como as CECILIAS e MINHOCÕES.

ARABAÇÚ - Macaco da região do baixo-Amazonas, Callicebus moloch (HoFFMANNSEGG), de côr acinzentada.

ARABOIA - Nome que, no Acre, se dá à C A N I N A N A, Spilotes pullatus pullatus (L.). Dá-se, também, a mesma designação vulgar à espécie Chironius fuscus (L.), também conhecida por UR U P I A G Á R A.

ARAÇARI DO MINHOCA - Nome vulgar da espécie Pteroglossus aracari.

ARAÇARI PRETO - Áve da familia Ramphastidae, das Guianas e norte do Brasil, Selenidera piperivora (L.).

ARACNIDEOS - Artrópodos providos de quatro pares de patas ambulatórias, dois pedipalpos e duas queliceras.

ARACÚ-BRANCO - Peixe da família Caracinidae, Leporinus mülleri GüNTHER.

ARACÚ-PINIMA - Peixe da familia Caracinidae, Leporinus affinis GÜNTHER.

ARAÇARÍ DE CABEÇA VERMELHA - Áve da familia Cracidae do norte do Brasil, Ortalis motmot motmot (L.) 
ARACŨ̃O - Áve da familia Cuculidae, do sul da Bahia, Espirito Santo e Minas Gerais, Neomorphus geoffroyi dulcis Snethlage.

ARAMÁ - Dever-se-ia corrigir serem estas abelhas realmente agressivas, mas, sendo desprovidas de ferrão não causam dano às pessoas, apenas são capazes de morder. Além disso, seria interessante acrescentar que estas Abelhas como as Meliponas (v. I R A P U I ) defendem a sua colmeia impregnando-a de um odor desagradavel que afugenta os inimigos para o que misturam fazes de mamiferos na argila que entra na composição da cera.

ARAMAÇÁ - Falta a indicação de que o peixe possue os dois olhos localisados num mesmo lado da face e que ésta muda de côr de conformidade com a iluminação que recebe.

ARANEÍDEOS - Aracnídeos dotados de abdomen não segmentado, preso ao cefalotórax por meio de pedúnculo muito delgado.

ARANHA - Acrescentar ao verbete Crustáceo decápodo marinho, da Subtribu Dromiacea, Superfamilia Thelxiopeidea, Latreillia elegans Roux, dotado de carapaça granulosa, olhos piriformes, pernas muito compridas e finas.

ARAPAÇÚ DOS COQUEIROS - Áve da familia Furnariidae, do norte do Brasil, Berlepschia rikeri (RIDGway).

ARAPAÇÛ GRANDE - Passeriforme da familia Dendrocolaptidae, Dendrocolaptes platyrostris platyrostris SPIX.

ARARINHA - Nome que se dá à MARACAN A, Purhura maracana (VIEILlot) e à espécie Orthopsittaca manilata (BoDD).

ARARINHA DE CABEÇA ENCARNADA - Nome dado ao Periquito Pyrhura picta lucianni (Deville).

ARAUIRI - Peixe da familia Caracinidae, Chalecinus auratus Cuv. \& VAL.,

ARATû - No litoral de S. Paulo é designação mais comum do Crustáceo Decápodo - Goniopsis cruentata, vermelho, muito veloz e que sobe nos arbustos do mangue. É um caranguejo semiterrestre com a particularidade de respirar o oxigênio do ar atmosférico ficando muito tempo fóra dágua. Para isso bastar-lhe-á manter apenas humedecidas as brânquias.

ARDEÍDAS - Áves Ciconiiformes, cujo tipo representativo é a G A R Ç A .

ARGONAUTA - Molusco acéfalo, dibrânquio, da família Argonautidae: Argonauta argo (L.) (E. de S. Paulo) e Argonauta geniculata Gould (R. de Janeiro). As fêmeas são dotadas de belissima concha.

ARIGBOIA - Nome pelo qual é conhecida a S U C U R I, Eunectes murinus (L.), no centro e na região litorânea brasileira. 
ARIRAMBA GRANDE - Nome que, no Amazonas, se dá ao MARTIM PESCADOR GRANDE, Megaceryle torquata torquata (L.).

ARIRAMBA DA MATA - Áve Piciforme, da familia Galbulidae, Galbula tombacea cyanescens Deville, do Norte do Brasil. Nome que se aplica, também, à espécie Brachyalba lugubris lugubris (SWAINSON).

ARIRAMBA MIUDINHO - Nome que, no Amazonas, se dá ao MARTIM PESCADOR PEQUENO, Chloroceryle inda (L.) bem como à espécie C. aenea aenea (PALL.).

ARIRAMBA PEQUENA - Nome que, no Norte do Brasil, se dá ao MARTIM PESCADOR PEQUENO, Chloroceryle americana americana (GMELIN).

ARPI - Nome de uma borboleta noturna, da familia Ceratocampidae, Adelocephala subangulata.

ARTRÓPODOS - Invertebrados dotados de exoesqueleto quitinoso e providos de apêndices articulados pares. Entre eles encontram-se os Insétos, os Aracnídeos, os Crustáceos e os Miriapodos.

ARUÁ - Seria de valia acrescentar que este molusco é noscivo e que estraga a folhagem e os brotos das plantas aquáticas, como registra o D.R.v.I., à custa dos dentes que, em número de vários milhares, aparecem enriçados no orgão bucal chamado rádula.

ASA DE MORCEGO - Nome dado a uma borboleta noturna. da familia Saturniidae, Loxolonia serpentina MAass.

ASGARIS - Diz-se dos Nematoides cujo típo é a L O M B R I G A. ASCÍDIA - Tunicados representados por formas sedentárias, dotadas de manto celulósico, muito comuns na zona costeira.

ASSENTA PAU - Nome de uma borboleta diurna da família Nymphalidae, Ageronia februa februa HuBn., também conhecida por CARIJÓ e ESTALADEIRA.

ASSENTA PAU DE BARRIGA VERMELHA - Nome de uma borboleta diurna, da familia Nymphalidae, Ageronia amphinome aegina FRUHST..

ASTEROIDEA - Classe de Equinodermas que abriga todas as "Estrelas do mar verdadeiras".

ATÉCOS - Divisão dos Quelônios em que se encontram exemplares desprovidos de escudos ou placas córneas.

AVISUGA - Nome, um tanto raro, de origem lusitana, mas ainda em uso pelos descendentes de portugueses residentes no Brasil, para designar todos os parasitos de áves.

AZUL SEDA - Nome de uma borboleta diurna, da família Morphoidae, Morpho menelaus L.,

AZULÃO - Nome dado a uma borboleta diurna, da familia Morphoidae, Morpho laertes GodT. 
AZULÃO BOIA - Nome dado a duas cobras áglifas, do gênero Leptophis, L. ahactulla e L. occidentalis nigromarginatus.

AZULÃO FERRETE - Nome dado a borboletas das familias Brassolidae e Nymphalidae, Eryphanes reevessii West e Ageronia arete arete DBL.,

AZULINHO - Nome dado ao Fringilideo Cyanoloxia glauco-caerulea (Lafresnaye \& D'Orbigny), ocorrente no R. G. do Sul, São Paulo e Mato Grosso.

Damos a seguir os sinonimos referentes à letra " $\mathrm{A}$ " que se encontram no D.R.V.I. e nestas Achegas. Na segunda coluna, mencionamos os títulos dos verbetes correspondentes.

SinôNimo

VERBETE

A B A C A T U A I A

A B A DE JO

ABELHA ESCURA

ABELHA MESTRA

ABELHA MULATA

ÄBELHA SOLITÁRIA

A B REU

A B R O T A

ABROTEA

ACALEFO

AC A NÁ

ACA A T I

ACANGAPEVA

$A C A N G U C$ Û́

ACAR Á - AÇ Û

ACAR A - A I A

A C.ARÁ-A PU A

A C A R Á - D I S C O

ACARÁ-FERREIRO

A C A R Á-1

ACARÁ-MUCÚ

ACARÁ-PARAGUÁ

ACARÁ-PINHACHAME

ACARÁ PINDÁ

ACARÁ PITANGA

ACARÁ TINGA

$A C A R A ́$ ÜNA

ACARINOS

ACTINEA

A CURA N A

A CURA A Á

A CURI

A C UXI

A FIDIO

A G ACHADEIRA

A G A M I

A GER Û

AGUA MA
Abacatáia

Badejo

Abelha do Reino

Abelhas sociais indigenas

Abelha

Abelha

Abelha

Abróte

Abróte

Cifozoário

Acauã

Acanatic

Cambéva

Onca out Onça Pintada

Apaiari

Caranha

Carapitanga

Mororé

Acará Topete

Acarai

Acará mocó

Acará fuso

Acará bererê

Agulha

Carapitanga

Acará

Acará péva

Carrapatos

Anêmona

Bacuráu

Bacuráu

Aguti

Cutia de rabo

Pulgōes

Massarico de coleira

Jacamin

Ajurú

Água viva 
A G U A P E A C O C A

AGUA SÓ

A GUARA GU A ÇÚ

AGUIA PESQUEIRA

A I - P IC H Û M A

A I A C Á

A I G

A I U S S Á

A J A J A

A JER Ú

A JURÛ́ CÁTINGA

A JURŨ CURÁU

AJURƯ ÊTE

A L A CR AU

ALBACORA BRANCA

A LCARAV $\tilde{O} O$

A L FINETE

A M ARELA

A MARELINHO

A MBORE

AMEIJÔA

AMORE GUAÇU

AMOREI A

A M P A L Á GUIA

ANAMBÉ GUACCÚ

ANAMBE POMBO

ANA VELHA

ANDORINHA DO CAMPO

ANDUIÁ

A NEI Ú

ANEMBE ÚNA

A NFISBENA

A GÃ - Hứ

A N G Û

A NHU - P.OCA

A NIJU.ACANGA

ANOJADO

A N Ú-A I

ANU-GUACQ Û

A N Û- $\mathrm{HU}$

A N UM

ANUM POCA

AN Û́ PRETO

A PAI

ARACARUNA

A R A GUAI I VA

A R A GuÁGuÁ

A R A GUAR I

ARAGUIR $\AA$

A R A N CIM

A R A P A IMA

ARAPONGA DA HORTA
Piaçoca

Narcejão

Guará

Aguia pescadora

Preguiça

Tracajá

$A i$

Aiassá

Colhereiro

Papagaio

Papagaio do mangue

Ajurú catinga

Papagaio

Alacrã

Albacora

Socó boi

Panaguaiú

Abelha

Cambacica

Amoré

Ameija

Emboré

Amoré

Sucuri

Anambé pitiut

Anambé pitiú

Socózinho

Taperá

Antujá

Ameija

Anambé preto

Cobra de 2 cabeças

Tapacanim

Japacanim

Anhuma póca

Camaleão comum

Antuiá

Anú

Anú

Anú coróca

Anú

Tachã

Anú

Irerê

Palombeta

Sabiá cica

Espadarte

Araguaí

Tico-tico rei

Iraxim

Pirarucú

Araponguinl:a 
ARAPONGUIRA

A R A P U ÇÁ

ARARA CANGUCú

ARARA PIRANGA

ARARA PRETA

ARARA ÚNA

A R A R I

A R A R U N A

AR A T A I Á

ARA TAIAÇû́

ARAAUÁ

ARAUAI

ARAUAI

AR A U A NÁ

ARREBITA RABO

A RUA I

A R UMA C Á

A R UM A R Ú

ASA BRANCA

A.SA DE TELHA

A S SOBIA CACHORRO

A TANGARÁ TINGA

A T I NGAÇ Ũ

A T I NGUẢ Çû

A T INGAƯ

A T U R I Á

AZULÃO BICUDO

AZULÃ DO CAMPO

AZUL IO DA SERRA

Araponguinha

Tracajá

Tracajá

Arara canga

Arara azul

Arara azul

Canindé

Arara azul

Arapapá

Arapapá

Aruá

Araguai

Aravari

Aruaná

Sabiá póca

Araguai

Aramaçá

Chopim

Pomba Trocaz

Vira

Japacanim

Rendeira

Alma de caboclo

Alma de cabôclo

Alma de gato

Cigana

Azulão

Sanhaço

Sanhaço 